\title{
Applying the 2005 Canadian Hypertension Education Program recommendations: 2. Assessing and reducing global atherosclerotic risk among hypertensive patients
}

E vidence from large population-based studies has confirmed that hypertension increases a patient's risk of cardiovascular disease about 2- to 3fold. Even after adjusting for other risk factors, the presence of borderline systolic hypertension $(\geq 160 \mathrm{~mm} \mathrm{Hg})$ alone increases the relative risk of a cardiovascular event by about 1.5 .

Conversely, lowering blood pressure is known to reduce the risk of major cardiovascular events. Antihypertensive treatment, for example, reduces the risk of coronary artery disease by about $15 \%$ and cerebrovas- cular events by about $35 \% .{ }^{1}$

However, hypertension is only 1 risk factor for cardiovascular disease, and it has become evident that a patient's prognosis depends on the number and severity of atherosclerotic risk factors present.

The 2005 Canadian Hypertension Education Program recommendations emphasize risk factor assessment in managing hypertension. ${ }^{2}$ Using 2 hypothetical clinical cases, we illustrate how global atherosclerotic risk is assessed and how those assessments are applied in hypertension management.
Brenda R. Hemmelgarn

Departments of Medicine and of Community Health Sciences

University of Calgary

Calgary, Alta.

Steven Grover

Division of Clinical Epidemiology

Montreal General Hospital

McGill Cardiovascular Health

Improvement Program

McGill University

Montréal, Que.

Ross D. Feldman

Robarts Research Institute

University of Western Ontario

London, Ont.

For the Canadian Hypertension

Education Program
CASE 1: James is a 45-year-old man in whom hypertension has recently been diagnosed. A smoker, he has a history of dyslipidemia. His blood pressure is currently $160 / 100 \mathrm{~mm} \mathrm{Hg}$, and laboratory results show a total cholesterol level of $6.8 \mathrm{mmol} / \mathrm{L}$, a low-density lipoprotein level of $5.2 \mathrm{mmol} / \mathrm{L}$, a triglyceride level of $3.2 \mathrm{mmol} / \mathrm{L}$, a high-density lipoprotein cholesterol (HDL-C) level of $1.0 \mathrm{mmol} / \mathrm{L}$, and a cholesterol:HDL-C ratio of 6.8 .

CASE 2: Sarah is a 45-year-old female marathon runner with hypertension. Her blood pressure has been consistently elevated at 160/100 mm Hg. She has no other atherosclerotic risk factors, and her blood lipid levels are excellent. She has a total cholesterol level of $5.8 \mathrm{mmol} / \mathrm{L}$, a low-density lipoprotein level of $3.7 \mathrm{mmol} / \mathrm{L}$, a triglyceride level of $1.3 \mathrm{mmol} / \mathrm{L}$, a HDL-C level of $1.8 \mathrm{mmol} / \mathrm{L}$, and a cholesterol:HDL-C ratio of 3.2.

Question: How do you determine the overall cardiovascular risk for patients with hypertension?

Comment: A number of methods to calculate a patient's absolute cardiovascular risk are now available, including the Framingham risk equation, the Cardiovascular Life Expectancy Model and the Dundee coronary risk disk. The Framingham risk equation is one of the most frequently used, and it takes into account age, sex, systolic and diastolic blood pressure, cholesterol levels, presence of diabetes mellitus and smoking status.
It estimates the 10-year risk of coronary artery disease (CAD) (defined as angina pectoris, recognized and unrecognized myocardial infarction, coronary insufficiency and CAD-related death).

Question: What are the 10year risks of CAD for James and Sarah?

Comment: Using the Framingham risk equations (http://hin .nhlbi.nih.gov/atpiii/calculator.asp ?usertype=prof or www.chiprehab .com/crd for a bilingual version calibrated for Canada), James has a $24.1 \%$ risk of CAD over the next 10 years. Although Sarah has the same blood pressure as James, her risk is much lower (4.1\%) since she has no other atherosclerotic risk factors.

Question: Would the benefit of treatment be greatest for Sarah, who has hypertension only, or for James, who has the same blood pressure elevation as Sarah but more atherosclerotic risk factors?

Comment: Although both randomized trials and observational studies have consistently demonstrated a continuous increase in the relative risk of cardiovascular disease with increasing levels of blood pressure, the absolute risk can in fact be higher at lower levels of blood pressure if other risk factors are present. Similarly, the absolute benefit of antihypertensive therapy depends not only on the blood pressure level but also on the absolute risk of disease based on the number of cardiovascular risk factors present. ${ }^{3}$ As shown in Table 1, the number of pa- 
tients needed to treat to prevent a CAD-related event at 10 years is much lower for James, in whom the absolute risk is higher, than for Sarah. Table 1 also illustrates that the effectiveness of treatment depends more on the absolute risk of disease than on the blood pressure level.

Question: If the greatest treatment benefit is experienced by patients with the most risk factors, should lower blood pressure targets be used for these high-risk patients?

Comment: The optimal target blood pressure for safely reducing the risk of cardiovascular events has been validated for patients with diabetes and hypertension but remains uncertain for patients with specific atherosclerotic risk factors. Among patients with diabetes, one of the groups at highest risk, the results of the Hypertension Optimal Treatment $(\mathrm{HOT})^{4}$ trial showed an approximate $50 \%$ reduction in major cardiovascular events for patients in the lowest category of target diastolic blood pressure ( $\leq 80 \mathrm{~mm} \mathrm{Hg}$ ) compared with the highest category ( $\leq 90 \mathrm{~mm} \mathrm{Hg}$ ). Optimal target blood pressures in other populations at high risk of cardiovascular disease remain to be determined.

Question: James has a number of risk factors that require treatment. Should any 1 risk factor in particular be targeted to achieve the greatest reduction in his risk of future cardiovascular events?

Comment: Given that the greatest impact in blood pressure lowering has been demonstrated among patients with the greatest number of risk factors, emphasis should be placed on targeting these high-risk populations. However, rather than targeting 1 risk factor alone, efforts should be made to treat all risk factors. Table 2 shows the impact of treating James's risk factors (returning lipid levels to normal and stopping smoking), as well as lowering his blood pressure. Treatment of each additional risk factor reduces his CAD risk and reduces the number needed to treat to prevent a CAD-related event at 10 years, compared with his original high-risk profile.

Question: Can these prediction models for estimating cardiovascular risk be applied to all populations?

Comment: Unfortunately, even well-validated models, when developed in one patient population, may be less accurate when applied to other populations. For instance, although the Framingham equations have been shown to reliably discriminate between low- and high-risk patients, they may be inaccurate

Table 1: Absolute coronary risk and number of patients needed to treat (NNT)* to prevent a coronary event over 10 years for 2 patients with different risk profiles, using Framingham estimates of coronary risk and change in blood pressure

\begin{tabular}{|c|c|c|c|}
\hline \multirow[b]{2}{*}{ Risk profile } & \multicolumn{3}{|c|}{ Absolute 10-year coronary risk } \\
\hline & $\begin{array}{l}\text { Baseline blood pressure } \\
\qquad 160 / 100\end{array}$ & $\begin{array}{c}\text { Blood pressure treated to } \\
\qquad 150 / 95\end{array}$ & $\begin{array}{c}\text { Blood pressure treated to } \\
139 / 89\end{array}$ \\
\hline $\begin{array}{l}\text { James } \\
\text { - male } \\
\text { - } 45 \text { yrs } \\
\text { - dyslipidemia } \\
\text { - smoker }\end{array}$ & $24.1 \%$ & $\begin{array}{c}22.2 \% \\
(\mathrm{NNT}=53)\end{array}$ & $\begin{array}{c}17.9 \% \\
(\mathrm{NNT}=16)\end{array}$ \\
\hline $\begin{array}{l}\text { Sarah } \\
\text { - female } \\
\text { - } 45 \text { yrs } \\
\text { - no other risk factors }\end{array}$ & $4.1 \%$ & $\begin{array}{c}3.3 \% \\
(\mathrm{NNT}=125)\end{array}$ & $\begin{array}{c}2.4 \% \\
(\mathrm{NNT}=59)\end{array}$ \\
\hline
\end{tabular}

*The NNT is calculated as NNT=1/ absolute risk reduction as a proportion.

Table 2: Absolute coronary risk and number of patients needed to treat (NNT) to prevent a coronary event over 10 years for 1 patient with a changing risk profile, based on Framingham estimates of coronary risk and change in blood pressure, lipid levels and smoking cessation

\begin{tabular}{lccc}
\hline & \multicolumn{3}{c}{ Absolute 10-year coronary risk } \\
\cline { 2 - 4 } $\begin{array}{l}\text { Risk profile for } \\
\text { 45-year-old male }\end{array}$ & $\begin{array}{c}\text { Blood pressure treated to } \\
150 / 95\end{array}$ & $\begin{array}{c}\text { Blood pressure treated to } \\
139 / 89\end{array}$ \\
\hline $\begin{array}{l}\text { - dyslipidemia } \\
\text { - smoker }\end{array}$ & $24.1 \%$ & $22.2 \%$ & $17.9 \%$ \\
\hline $\begin{array}{l}\text { - lipid levels back to normal } \\
\text { - has stopped smoking }\end{array}$ & $9.4 \%$ & $(\mathrm{NNT}=53)$ & $(\mathrm{NNT}=16)$ \\
\hline
\end{tabular}

*The NNT is calculated on the assumption that returning lipid levels to normal and stopping results in an absolute risk reduction comparable to those who have never smoked and never had dyslipidemia. 
in estimating absolute cardiovascular risks. The estimate of absolute risk may require additional calibration for a specific population. If potential limitations are recognized, these prediction models still have an important role to play in assessing risk and guiding treatment.

This article has been peer reviewed.

Competing interests: Brenda Hemmelgarn has received funding for an investigatorinitiated clinical trial from Hoffman La

Roche. Ross Feldman has participated in CME programs and received consulting fees from Abbott/Fournier, Aventis/SanofSynthelabo, Bayer, GSK/Boehringer-Ingleheim, Merck-Frosst, Pfizer, Servier and Solvay. He has received grants-in-aid from Pfizer. Steven Grover has received remuneration for developing and testing different global cardiovascular risk assessment tools that are freely available to patients and health care professionals. He has also served as the principal investigator on in- dustry-sponsored, investigator-initiated, clinical trials assessing the usefulness of global risk assessment in clinical practice.

\section{References}

1. Psaty BM, Lumley T, Furberg CD, Schellenbaum G, Pahor M, Alderman $\mathrm{MH}$, et al. Health outcomes associated with various antihypertensive therapies used as first-line agents. 7AMA 2003;289:2534-44.

2. Hemmelgarn BR, McAlister FA, Myers MG, McKay DW, Bolli P, Abbott $\mathrm{C}$, et al. The 2005 Canadian Hypertension Education Program (CHEP) recommendations for the manage- ment of hypertension: Part 1 - Blood pressure measurement, diagnosis, and assessment of risk. Can 7 Cardiol 2005; 21(8):645-56.

3. Ogden LG, He J, Lydick E, Whelton PK. Long-term absolute benefit of lowering blood pressure in hypertensive patients according to the JNC VI risk stratification. Hypertension 2000;35:539-43.

4. Hansson L, Zanchetti A, Carruthers SG, Elmfeldt D, Julius S, Menard J, et al. Effects of intensive blood-pressure lowering and low-dose aspirin in patients with hypertension: principal results of the Hypertension Optimal Treatment (HOT) randomized trial. Lancet 1998;351:1755-62.

\section{Articles to date in this series}

McAlister FA, Wooltorton E, Campbell NRC. The Canadian Hypertension Education Program (CHEP) recommendations: launching a new series. CMAJ 2005;173(5):508-9.

Bolli P, Myers M, McKay D. Applying the 2005 Canadian Hypertension Education Program recommendations: 1. Diagnosis of hypertension. CMAJ 2005;173(5):480-3.

\section{Clinical trial registration}

CMAJ will consider clinical trials for publication only if they have been registered in a publicly accessible clinical trials registry before the enrolment of the first patient. This policy applies to trials that start recruiting on or after July 1, 2005. For trials that began enrolment before this date, registration is required by Sept. 13, 2005. The criteria for acceptable registration are described in CMAJ (2005;172[13]:1700-2). 